\title{
Correlation between fibre length characteristics and mechanical properties of Tectona grandis wood
}

\author{
D. N. Izekor ${ }^{1 *}$ and J . A. F uwape ${ }^{2}$
}

${ }^{1}$ Department of Forestry and Wildlife, University of Benin, P.M.B. 1154, Benin City, NIGERIA

${ }^{2}$ Department of Forestry and Wood Technology, Federal University of Technology, P.M.B.704, Akure, NIGERIA

*Corresponding author. E-mail: nosakhare.izekor@uniben.edu

Received: August 3, 2012; Revised received: September 1, 2012; Accepted: 0 ctober 10, 2012

Abstract: This study considered the relationship between fibre length characteristics and mechanical properties of Tectona grandis wood aged 15, 20 and 25-year. Six trees of even aged and similar class diameter were used for the study. Wood samples used for the study were systematically collected from three portions at 10,50 and $90 \%$ of the tree height. The test samples were prepared along the radial positions from the pith to the bark. The relationship between fibre length and mechanical properties were examined using linear regression models and correlation coefficient. The results obtained from the correlation analysis carried out to examine the linear relationship between fibre length and mechanical properties of $\mathrm{T}$. grandis wood were $0.924,0.929$ and 0.940 for MOR, MOE and CS parallel to grain. The relationship was highly significant $(p<0.05)$. Also the correlation coefficient $(r)$ between fibre length and mechanical properties of T. grandis wood were highly significant $(p<0.001)$. Therefore, fibre length characteristics can be used as an index in predicting the mechanical properties of T. grandis wood.

Keywords: Correlation coefficient, Fibre length, Linear models, Mechanical properties, Tectona grandis wood

\section{INTRODUCTION}

Tectona grandis is an exotic hard wood timber species belonging to the family Verbenaceae. It is one of the most valuable timber tree species in the world due to its high quality timber, attractiveness and durability of the wood it produce (Goh and Monteuuis, 1997). Wood is one of the oldest and best known structural materials. It has been described as the third most valuable resources in the world after petroleum and natural gas (WRI 1990). Wood is a desirable material for construction and is extremely versatile in its utilization. Fibre length and mechanical properties of wood have been reported to show gradual increase from pith to bark with a corresponding decrease from the tree base base to the top (Izekor and Fuwape, 2010; 2011). Wood fibre length is one of quality parameters for pulp wood (Sandercock et al, 1995; Jorge, et al, 2000). Its dimension are determined by the dimensions of the cambial fusiform cells from which they are derived and by the process that occurs during cell differentiation (Ridout and Sands, 1993; 1994). The variation in mechanical properties among trees of the same and different age classes of T.grandis have earlier been studied (Izekor and Fuwape, 2010). Mechanical properties were observed to have increased values with increasing trend in fibre length characteristics. Also the variations in the anatomical properties of T. grandis wood have been reported (Izekor and Fuwape, 2011). The objective of the study was to examine the correlation between fibre length characteristics and mechanical properties of Tectona grandis wood using correlation coefficients and regression equation models.

\section{MATERIALS AND METHODS}

Study A rea: Wood samples of T. grandis were collected from Edo State Forestry plantation. The forest plantation lies between latitude $5^{\circ} 45^{\prime}$ and $7^{\circ} 8^{\prime}$ north and longitude $5^{0} 4^{\prime}$ and $6^{0} 52^{\prime}$ 'east. The climate of the area is tropical with distinct wet and dry season characterized by humid conditions in the south and sub-humid conditions in the north. The rainfall pattern of the state is bimodal and varies from $2000 \mathrm{~mm}$ a year in the humid southern part to $1150 \mathrm{~mm}$ a year in the sub-humid northern parts. The mean monthly temperature is about $27^{\circ} \mathrm{C}$ with a range of $22-35^{\circ} \mathrm{C}$ while the relative humidity range is from $79-90 \%$ (FORMECU, 1999). The topography of the area is generally flat with pockets of gentle undulation.

Six trees were randomly selected from each even aged stand of T. grandis plantation in accordance with the procedure of ASTM D143-83 standard (ASTM, 1983). Sample trees with very close diameter classes, relatively straight stem and clear wood were selected. Test samples for the study were systematically collected from the inner wood section near the pith) and outer wood section (close to the bark) while the middle wood was collected from midpoint between the inner wood and the outer wood section of the felled trees. The samples were conditioned ISSN : 0974-9411 (Print), 2231-5209 (Online) All Rights Reserved @ Applied and Natural Science Foundation www.ansfoundation.org 
to $12 \%$ moisture content in a controlled laboratory at the time of the test. The experiment was carried out as a four factor factorial in a completely randomized designed. Mechanical properties determination was carried out in accordance with British Standard Methods (BS, 1989). The static bending test from which the modulus of rupture (MOR) and modulus of elasticity (MOE) were evaluated using specimen size $20 \mathrm{~mm} \times 20 \mathrm{~mm} \times 300 \mathrm{~mm}$. The test was a centre-loading supported on a span of $280 \mathrm{~mm}$ while the force was applied on the radial face at mid span using a loading rate of $0.1 \mathrm{~mm} / \mathrm{min}$ on a Hounsfield Tensiometer machine. The MOR was calculated from the maximum load at which each wood sample failed. The MOE was calculated using load to deflection curve plotted on a graph by the Tensiometer machine. Compressive strength (CS) parallel to grain was determined by subjecting specimen size $20 \mathrm{~mm}$ x $20 \mathrm{~mm}$ x $60 \mathrm{~mm}$ wood samples to test on a universal static bending machine and a Compressiometer in accordance with British standard specification (Beaudom et al, 1989).

Fibre length determination was carried out using wood samples measuring $20 \mathrm{~mm} \times 20 \mathrm{~mm} \times 30 \mathrm{~mm}$. The test samples were softened by boiling for 24 hours in a beaker of water over a hot plate. Thin sections of 20 microns were prepared from three well oriented planes i.e cross sectional, transverse radial longitudinal sections (R.L.S.) and tangential longitudinal sections (T.L.S.) respectively, using a microtone slicing machine according to the procedure adopted by Gills and Onuga (1984). The microtoned wood sections were placed into petridishes containing methylated spirit for moistening. Staining was immediately done by adding drops of sefranin solution to the sections in the petridish and left for ten minutes. The stained wood sections were dehydrated with $95 \%$ ethyl alcohol (ethanol) for about 60 seconds and were cleaned using cedar wood oil as a cleaning agent. This facilitated easy lifting of section during mounting.

Dimensions of cells from each representative sample were on the average of 25 measurements according to Jorge et al (2000). One section each was lifted from the petridish with the aid of a forceps into a slide and trimmed to sizes for coverage with a slide cover of $2 \mathrm{~cm}$ square. Filter paper was used to mop up excess oil. Canada balsam was added to the slide and cover with slid. The prepared slide was placed over a hot plate to expel air bubbles and also effect even spread of Canada balsam on the slide. The slides were observed under photomicrograph electronic microscope with tracer reflector and this brought out the fibre characteristics of the wood for easy measurement. Statistical analysis: Regression analysis was carried out to examine the magnitude and pattern of relationship between fibre length characteristics and mechanical properties of $\mathrm{T}$. grandis wood while correlation coefficient was carried out by pairing the fibre length and mechanical properties of T. grandis wood to examine the linear relationship between them.

\section{RESULTS AND DISCUSSION}

Wood fibre length: The mean fibre length values obtained in this study were $1.45,1.73$ and $1.96 \mathrm{~mm}$ for the three age classes of 15, 20 and 25-year old T. grandis wood. Fibre length increase in value from 1.37 to $1.51,1.63$ to 1.82 and 1.80 to $2.15 \mathrm{~mm}$ at the inner wood through the middle wood to the outer wood among the three age classes of T. grandis wood respectively (Table 1).

Therefore fibre length increase with the increasing age of the tree irrespective of the tree portion where the wood sample is collected. The difference in fibre length associated with increase in height is mainly due to the differences in juvenile and mature wood proportion in the tree. This is because the proportion of juvenile wood increases with an increase in height (Zobel and Buijtenen, 1989). The general decrease in fibre length of T. grandis from the tree base to the top has earlier been reported (Izekor and Fuwape, 2011). The observed decrease in wood fibre length could be attributed to the influence of growth promotion substances which are close to the growing tip. These growth promoting substance initiates rapid production of cells at the tip with decreasing maturation time thereby resulting in the production of short cells at the tree top. The increase in fibre length from the inner wood through the middle wood to the outer wood could be attributed to the increase in the length of the cambial initials with increasing cambial age. M echanical properties: The mechanical properties of T. grandis wood studied in this work were those of MOR, MOE and CS parallel to grain. The MOR values obtained for T. grandis wood were 76.86, 103.95 and $134.69 \mathrm{~N} \mathrm{mm-}$ ${ }^{2}$ for ages 15, 20 and 25-year respectively (Table 1). Also MOR values increased from 67.19 to $86.35,96.00$ to 112.89 and 125.20 to $144.25 \mathrm{~N} \mathrm{~mm}^{-2}$ at the innerwood, middlewood and outerwood respectively (Table 1). The values obtained for MOE were 6846.92, 9920.54 and $1284.57 \mathrm{~N} \mathrm{~mm}^{-2}$ for ages 15, 20 and 25-year old T. grandis wood respectively while the mean values obtained for MOE at the radial positions were 6117.47 to 7628.86 , 9187.50 to 10724.68 and 12006.94 to $13745.28 \mathrm{~N} \mathrm{~mm}^{-2}$ for ages 15, 20 and 25-year old T. grandis wood respectively (Table 1). The mean values obtained for CS parallel to grain for the three age classes of 15,20 and 25-year old T. grandis wood were 43.74, 58.47 and $75.36 \mathrm{~N} \mathrm{~mm}^{-2}$ respectively. The mean values obtained at the radial positions ranged from 37.82 to $49.30,52.98$ to 64.30 and 68.15 to $83.20 \mathrm{Nmm}^{-2}$ at the innerwood, middlewood and outerwood respectively for the three age classes of $T$. grandis wood (Table 1).

The mechanical properties values obtained in this study increased with the age of the tree from 15-year through 
Table 1. Fibre length and mechanical properties values of T. grandis wood.

\begin{tabular}{llcccc}
\hline & & \multicolumn{3}{c}{ Par ameter stested } & \\
\hline Age (Y ear s) & Radial position & $\begin{array}{c}\text { Fibre length } \\
\mathrm{mm}\end{array}$ & $\begin{array}{c}\mathrm{M} \mathrm{OR} \\
\mathrm{N} \mathrm{m} \mathrm{m}\end{array}$ & $\begin{array}{c}\mathrm{M} \mathrm{E} \mathrm{E}^{-2} \\
\mathrm{~N} \mathrm{~mm}^{-2}\end{array}$ & $\begin{array}{c}\mathrm{CS} \\
\mathrm{Nm}^{-2}\end{array}$ \\
\hline \multirow{2}{*}{15} & Outer wood & $1.51 \pm 0.14$ & $86.35 \pm 9.57$ & $7628.86 \pm 1130.52$ & $49.30 \pm 7.78$ \\
& Middlewood & $1.47 \pm 0.13$ & $77.04 \pm 12.90$ & $6794.44 \pm 1182.13$ & $44.11 \pm 6.98$ \\
& Innerwood & $1.37 \pm 0.09$ & $67.19 \pm 12.24$ & $6117.47 \pm 822.48$ & $37.82 \pm 555$ \\
& Pooled Mean & $1.45 \pm 0.07$ & $76.86 \pm 9.58$ & $6846.92 \pm 757.06$ & $43.74 \pm 5.75$ \\
20 & Outer wood & $1.82 \pm 0.14$ & $112.89 \pm 14.78$ & $10724.68 \pm 1152.06$ & $64.30 \pm 8.38$ \\
& Middlewood & $1.73 \pm 0.14$ & $102.95 \pm 12.58$ & $9846.44 \pm 1095.65$ & $58.13 \pm 7.71$ \\
& Innerwood & $1.63 \pm 0.13$ & $96.00 \pm 13.12$ & $9187.50 \pm 992.67$ & $52.98 \pm 7.20$ \\
& Pooled Mean & $1.73 \pm 0.10$ & $103.95 \pm 13.49$ & $9919.54 \pm 771.19$ & $58.47 \pm 5.67$ \\
& Outer wood & $2.15 \pm 0.19$ & $144.25 \pm 12.04$ & $13745.28 \pm 1508.07$ & $83.20 \pm 11.63$ \\
& Middlewood & $1.92 \pm 0.15$ & $134.62 \pm 14.05$ & $12786.50 \pm 1549.86$ & $74.72 \pm 8.89$ \\
& Innerwood & $1.80 \pm 0.14$ & $125.20 \pm 14.95$ & $12006.94 \pm 1462.42$ & $68.15 \pm 9.71$ \\
& Pooled Mean & $1.96 \pm 0.18$ & $134.69 \pm 9.53$ & $12845.57 \pm 869.68$ & $75.36 \pm 7.55$ \\
\hline
\end{tabular}

Mean \pm SD of 6 replicates sampled trees of T. grandis wood

Table 2. Correlation ( $\mathrm{r}$ values) between fibre length and mechanical properties of T. grandis wood.

\begin{tabular}{lcccc}
\hline & Fibrelength & M OR & M OE & CS \\
\hline Fibre Length & 1.000 & $0.924 * *$ & $0.929 * *$ & $0.940^{* *}$ \\
MOR & $0.924 * *$ & 1.000 & $0.983^{* *}$ & $0.963^{* *}$ \\
MOE & $0.929 * *$ & $0.983^{* *}$ & 1.000 & $0.956^{* *}$ \\
CS & $0.940^{* *}$ & $0.963^{* *}$ & $0.956^{* *}$ & 1.000 \\
\hline
\end{tabular}

**significant $(\mathrm{p}<0.001)$ probability level

20-year to 25-year old T. grandis wood. The observed increased in mechanical properties with increasing age of the tree were due to increment of annual rings, addition of more mature wood and the increasing age of the cambium as the tree grows in girth (Izekor and Fuwape, 2010). Also mechanical properties values increased consistently from the innerwood through the middlewood to the outerwood for the three ages classes of 15, 20 and 25-year old T. grandis wood respectively. These increasing trends in mechanical properties values from the innerwood to the outerwood were associated to variations in some morphological factors such as fibre length, fibre diameter and wall thickness (Fuwape and Fabiyi, 2003).

R elationship between fibre length and mechanical proper ties of T. grandis wood: The results obtained from the correlation analysis carried out to examine the linear relationship between fibre length and mechanical properties were $0.924,0.929$ and 0.940 for MOR, MOE and CS parallel to grain (Table 2). This relationship was highly significant at 0.001 probability level. Regression analysis was used to develop mathematical model using mean fibre length values to predict the relationship between fibre length and the variations in MOR, MOE and CS parallel to grain. The following equation was developed from the model, $\mathrm{MOR}=94.93 \mathrm{x}-57.34, \mathrm{MOE}=$ $9659 x-6670$ and $C S=55.68 x-36.12$. The coefficients of determination $\left(\mathrm{R}^{2}\right)$ for the regression model were 0.854 , 0.863 and 0.882 for MOR, MOE and CS parallel to grain (Table 3).

Graphical representation showing the relationship existing between fibre length and mechanical properties such as MOR, MOE and CS parallel to grain are presented as scattered diagram (Fig. 2).

Three main strength properties were considered in investigating the relationship between fibre length and mechanical properties of T. grandis wood. These were MOR, MOE and CS parallel to grain. The correlation coefficients $(r)$ between fibre length and mechanical properties were highly significant $(\mathrm{p}<0.001)$. When the pooled mean values along the tree height were used, the

Table 3. Regression equation between fibre length and mechanical properties of T. grandis wood.

\begin{tabular}{lcc}
\hline Equation models & $R$ & $R^{2}$ \\
\hline MOR $=94.93 \times-57.34$ & 0.924 & 0.854 \\
MOE $=9659 x-6670$ & 0.929 & 0.863 \\
$\mathrm{CS}=55.68 \mathrm{x}-36.12$ & 0.940 & 0.882 \\
\hline
\end{tabular}




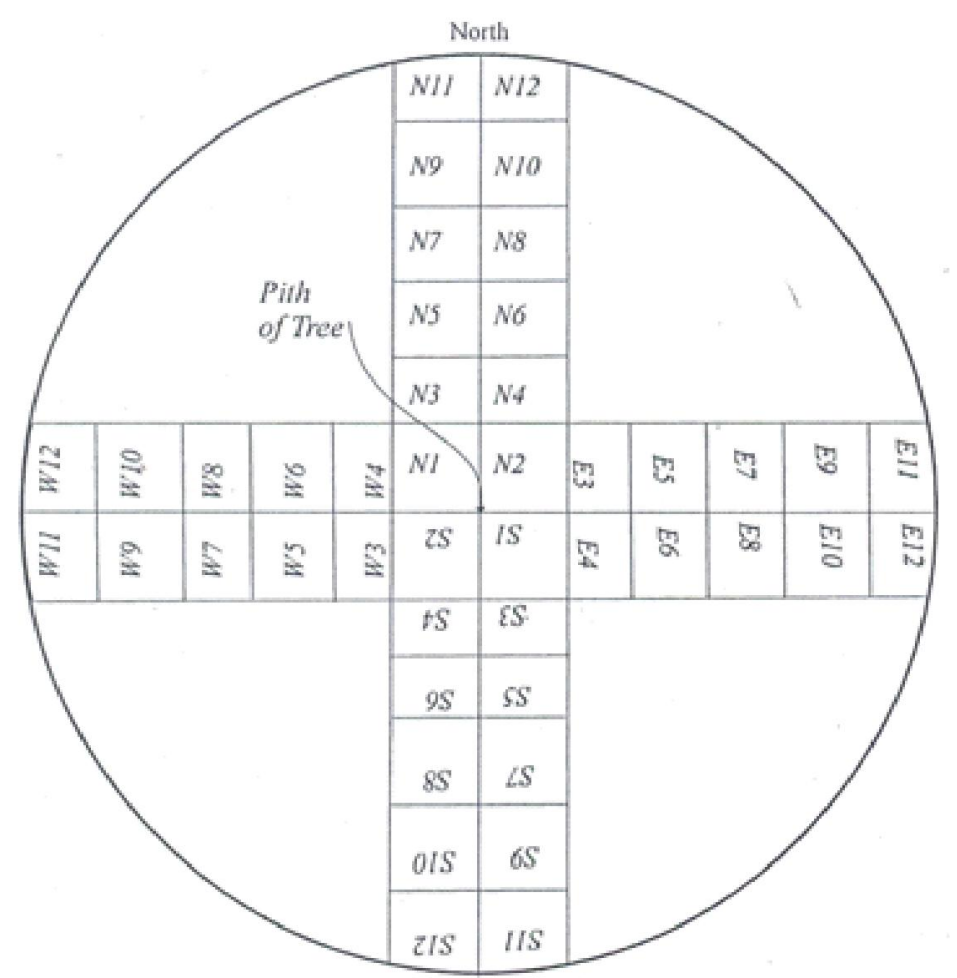

Fig. 1. Sketch showing method used in cutting up the bolts and marking the sticks. Source: ASTM D $143-83$ standard.

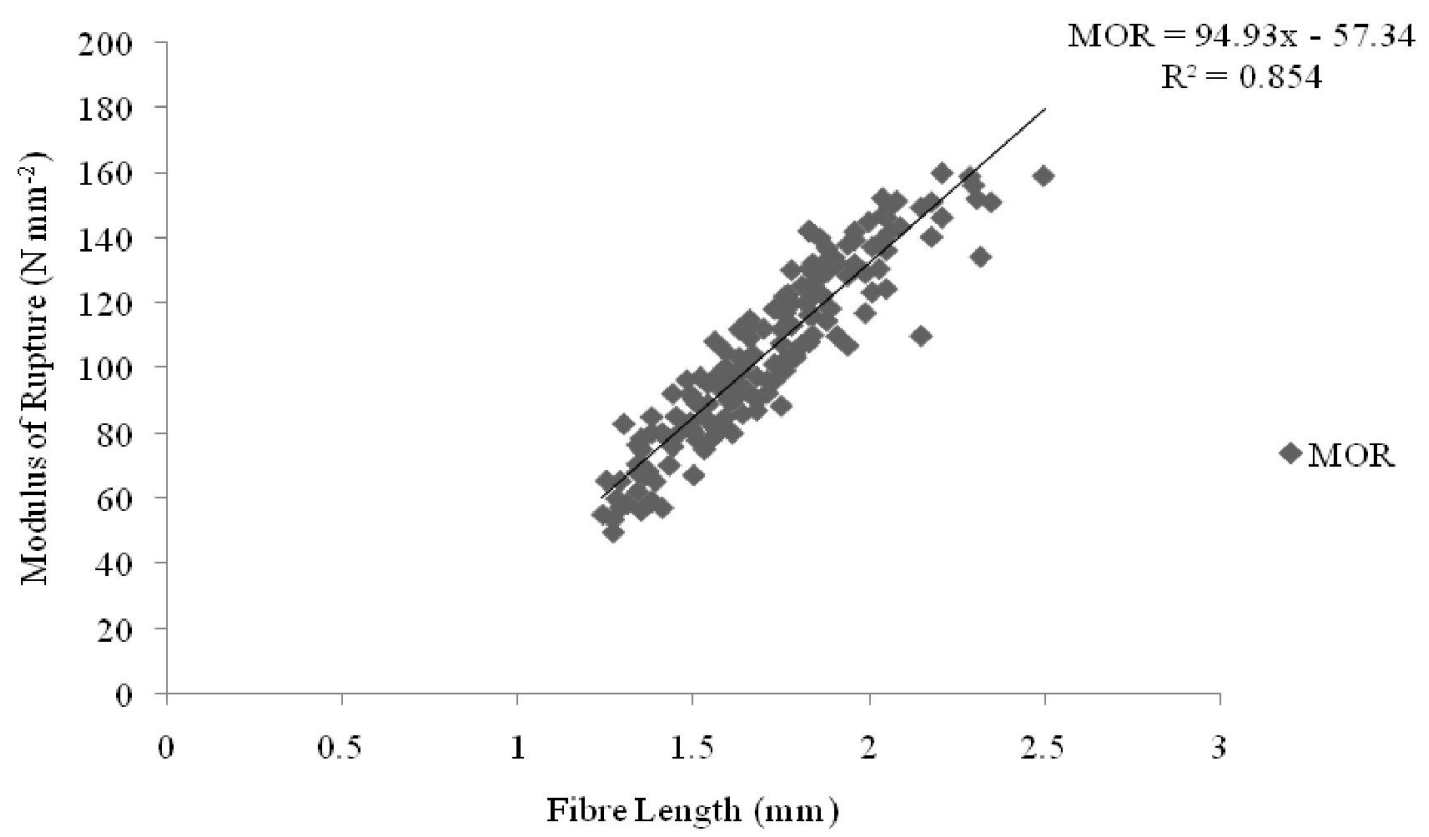

Fig.2. Relationship between fibre length ( $\mathrm{x}$ ) and M OR of T. grandis wood.

correlation coefficient between fibre length and mechanical properties were positively correlated. Simple linear regression models were used in examining the relationship between fibre length and mechanical properties of T. grandis wood. The results showed that fibre length have a strong positive effects on mechanical properties (Tables 2-3). Also, the coefficients of multiple determinations showed a high positive correlation between fibre length and mechanical properties of $T$. grandis wood. The linear equations models gave the best fit for the relationship (Figs. 2 - 4). Fibre length is a major contributor to the mechanical properties of T. grandis wood and can therefore be used in predicting its strength. The positive correlation between fibre length and mechanical properties considered in this study confirms earlier report, that strength of wood is related to the relative proportions of the various cell types in wood and even more so to the cell wall thickness of any one 


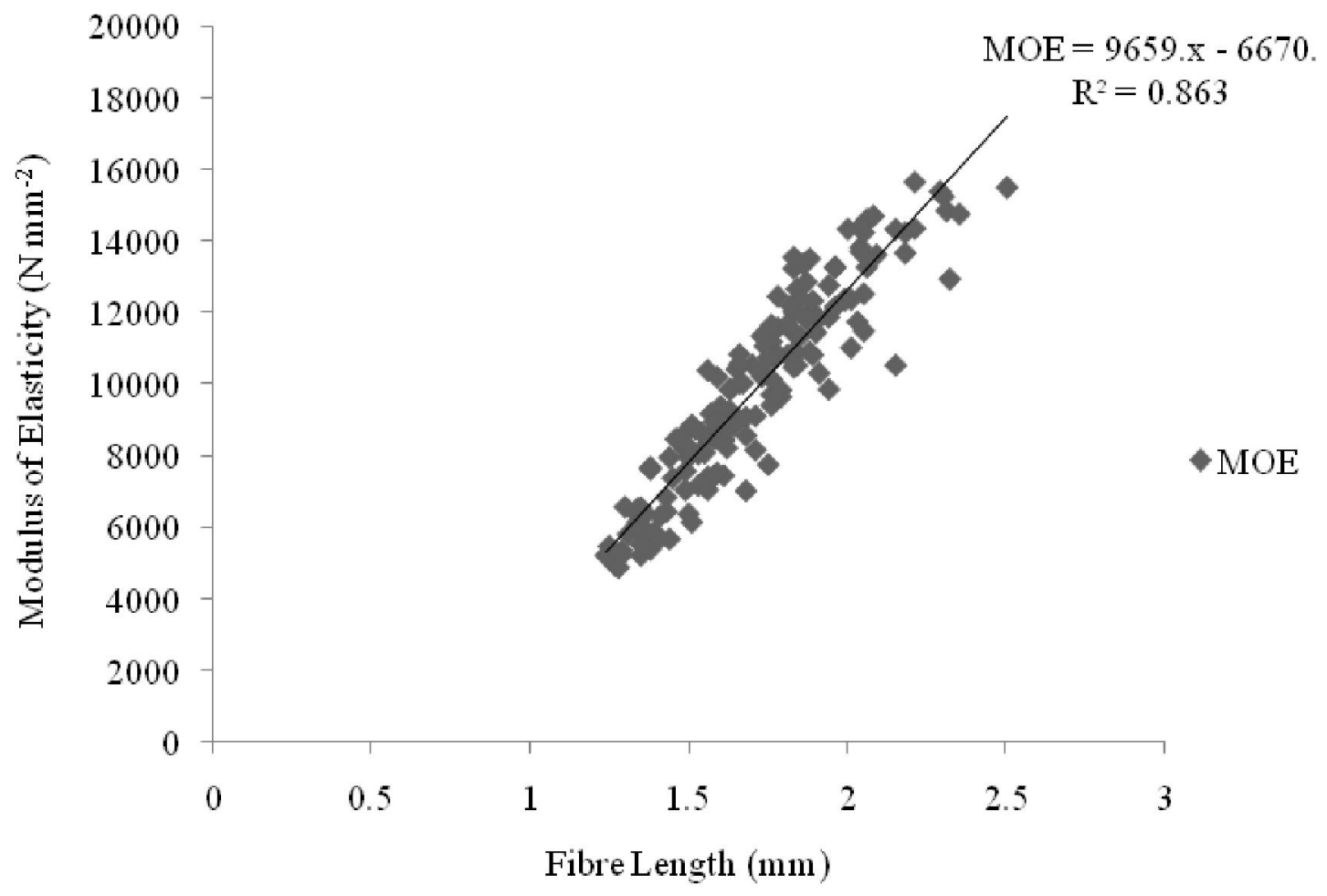

Fig. 3. Relationship between fibre length $(\mathrm{x})$ and $\mathrm{M} O \mathrm{E}$ of $\mathrm{T}$. grandis wood.

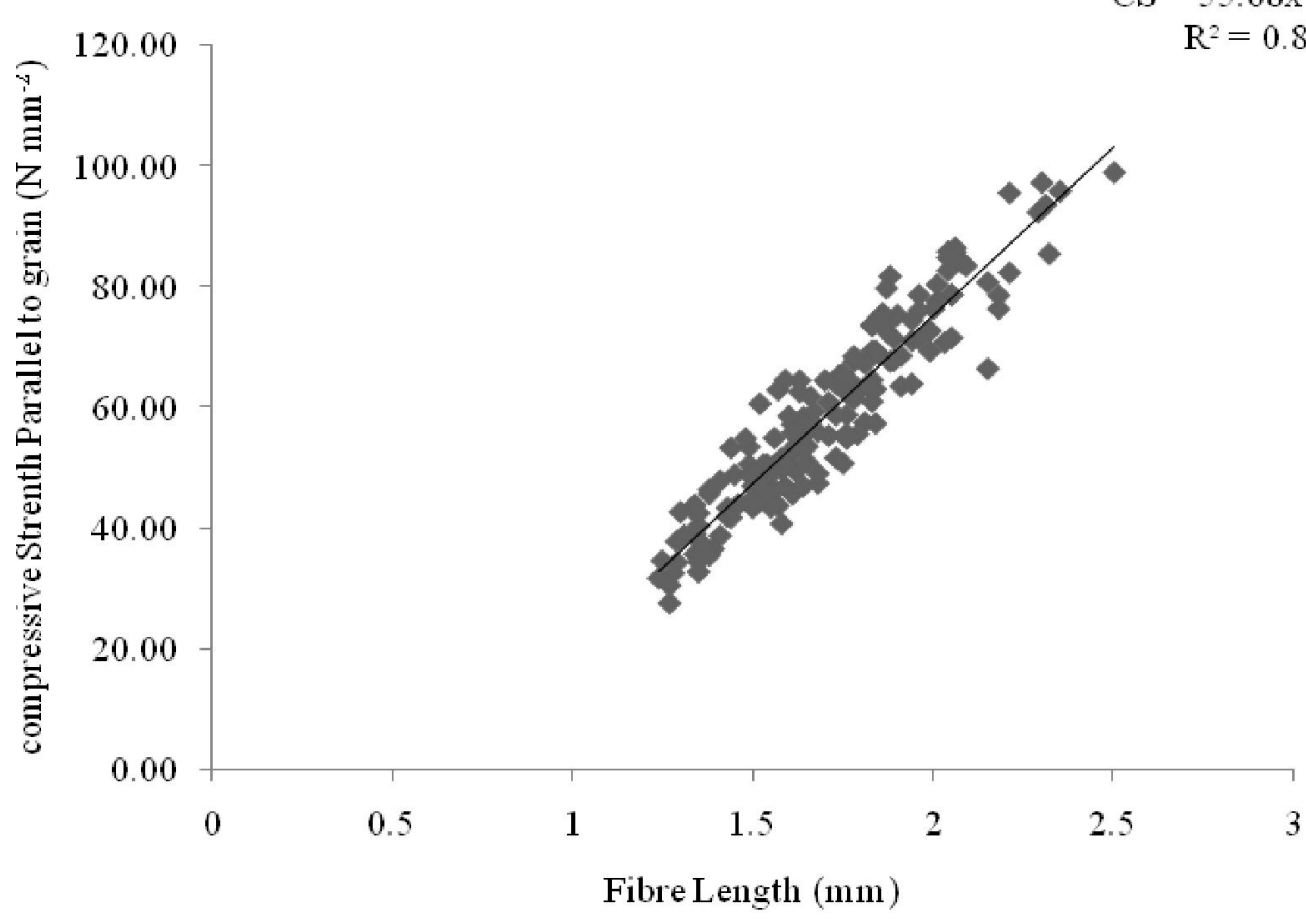

Fig.4. Relationship between fibre length $(x)$ and CS parallel to grain of $T$. grandis wood.

type (Dinwoodie, 1989). The findings also agree with previous report on the relationship between strength and anatomical properties of some Celtis species viz; Celtis adolpfi-friderici, C. mildbraedii, C. wightii and C. zenkeri (Ocloo and Laing, 2003). The authors reported a strong positive correlation between strength and anatomical properties of these species.

\section{Conclusion}

The three main strength properties considered in investigating the relationship between fibre length and mechanical properties of T. grandis wood were MOR, MOE and CS parallel to grain. The relationship between fibre length and mechanical properties of these wood were highly significant influencing the variations in its 
mechanical properties. The linear equation models gave the best fit for the relationship. Thus, fibre length is a major contributor to the mechanical properties of $\mathrm{T}$. grandis wood and can therefore be used in predicting its strength.

\section{REFERENCES}

ASTM (1983). American Society for Testing and Materials. Standard methods for testing Small clear specimen. ASTM 143-83. Philadelphia Pa. 48-105.

British Standard Institution (1989). BS373 Methods of Testing clear small specimen of Timber. British Standard Institution, London. 20pp.

Beaudom, M; M ansanga, B.O; Poliquin, J. And Beauregard, R.I. (1989). Physical and Mechanical properties of plantation grown Tamarck. Forest Product J ournal, 39 (6): $5-10$.

Dinwoodie, J.M. (1989). Wood, Nature cellular, polymeric fiber composite. Pub. The Inst. of Metals. London 88pp.

FORMECU (1999). Forest Resources Study: Reversed Forest Management Plan of Edo State. 126pp. Published by Beaks and Geomatics Nigeria Limited.

Fuwape, J.A. and Fabiyi, J.S. (2003). Variations in strength properties of Plantation grown Nauclea diderichii wood. J ournal of Tropical F orest P roducts, 9 (1\&2): 45-53.

Goh, D. and Monteuuis, O. (1997). Vegetation propagation of Teak. ITTO Newsletter, 7(2): 12-33.

Gills, L.S. and Onuga, J.E. (1984). A comparative study of the treachery elements of some commercial woods of Nigeria. Feddes Repertorium, 95: 645 - 655.
Izekor, D.N. and Fuwape, J.A. (2010). Variations in Mechanical Properties among Trees of the same and different age classes of Teak (Tectona grandis L.F.) wood. J ournal of Applied Sciences Research, 6 (4): 562 - 567.

Izekor, D.N. and Fuwape, J.A. (2011). Variations in Anatomical characteristics of Teak (Tectona grandis L.F.) wood. Archives of Applied Science Research. 3 (1):83-90.

Jorge, F; Quilho,T. and Pereira, H.(2000).Variability of fibre length in wood and bark in Eucalyptus globules, IAWA Journal, .21 (1): 41-48.

Ocloo, J.K. and Laing, E. (2003). Correlation of relative density and strength properties with anatomical properties of the wood of Ghana celtis species. Discovery and Innovation , 15 (314): 186-197

Ridoutt, B.G. and Sands, R. (1993). Within-tree variations in cambial anatomy and xylem cell differentiation in Eucalypttus globules. Trees, 8: 18-22.

Ridoutt, B.G. and Sands, R. (1994). Quantification of the process of secondary xylem Fibre development in Eucalyptus globules at two height levels, IAWA J ournal 15:417-424.

Sandercock, C.F; Sands, R;Rideoutt, B.G; Wilson, L.F. and Hudson, I. (1995). Factors Determining wood microstructure in Eucalyptus. In: B.M. Potts, N.M.G. Borralho J.B. Reid, R.N Cromer, W.N. Tibbits and C.A.Raymond (eds), Eucalyptus Plantations: Improving fibre yield and quality: CRC FOR Temperate Hardwood Forestry. Hobart. 5-9 pp.

WRI (1990). Development Report. World Resources Institute. Washington, D.C. United States.

Zobel, B.J. and Buijtenen, J.P. (1989). Wood variations: Its Causes and control. Springer-Verlag Series Berlin. 189 pp. 